\title{
Biosíntesis de dextranos de alto peso molecular mediante la inoculación con Leuconostoc mesenteroides, var. mesenteroides (ATCC 10830) de jugos residuales de la agroindustria de la piña: síntesis y caracterización de hierro-dextranos
}

\section{Biosynthesis of high molecular weight dextrans by inoculation with Leuconostoc mesenteroides, var. mesenteroides (ATCC 10830) residual juice from pineapple agroindustry: synthesis and characterization of iron-dextrans}

Vega Baudrit, José Roberto ${ }^{(1,2)}$, Sibaja Ballestero, María del Rosario ${ }^{(1)}$, Lopretti, Mary ${ }^{(3)}$

(1) Escuela de Química, Universidad Nacional, Heredia, Costa Rica - ${ }^{(2)}$ Laboratorio Nacional de Nanotecnología LANOTEC-CeNAT, Costa Rica - ${ }^{(2)}$ Laboratorio de Bioquímica y Biotecnología, Facultad de Ciencias, UdelaR, Uruguay Contacto: jvegab@hotmail.com, maria.sibaja@gmail.com

Recibido: 13/6/2012 - Aprobado: 20/11/2012

Resumen

En este trabajo se muestran los estudios realizados para obtener dextranos a partir de desechos de la agroindustria de piña. La fermentación se llevó a cabo en un biorreactor $(10 \mathrm{~L})$, se inoculó con un cultivo de Leuconostoc mesenteroides, var. mesenteroides (ATCC 10830). Se centrifugó y se precipitó y purificó con etanol. Fue caracterizado por medio de viscosidad, peso molecular y grupos funcionales por espectroscopía infrarroja. Este dextrano fue tratado con el fin de obtener hierro-dextranos.

Palabras clave: Polímeros, dextrana, hierro-dextrana.

\begin{abstract}
$\underline{\text { Abstract }}$
In this work we report studies for dextrans from pineapple agroindustrial-wastes. Fermentation was carried out in a bioreactor $(10 \mathrm{~L})$ where the juice was inoculated with a culture of Leuconostoc mesenteroides, var. mesenteroides (ATCC 10830). It was centrifuged, and precipitated and purified with ethanol. It was characterized by viscosity, molecular weight and functional groups by infrared spectroscopy. This dextran was treated to obtain iron-dextran.

Keywords: Polymer, dextran, iron-dextran.
\end{abstract}

\section{Introducción}

Dextrano es el nombre que colectivamente se le da a un gran grupo de exopolisacáridos bacterianos. Químicamente son $\alpha$-Dglucanos con predominio de enlaces glucosídicos 1-6 (Figura 1). La estructura, el peso molecular y otras propiedades de los dextranos son muy específicas de acuerdo al microorganismo utilizado para su obtención (Monsan, 1981).

Los dextranos son producidos por acción de la enzima dextransacarasa, que actúa sobre la sacarosa generando glucosa, y que se enlaza mediante radicales libres con la consiguiente liberación de la fructosa. Microbiológicamente son producidos por bacterias de los géneros Leuconostoc, Streptococcus y Lactobacillus y por algunos hongos del género Penicillium (Barker y Ajongwen, 1990).

Este tipo de material es ampliamente usado en el tratamiento clínico-terapéutico de animales y humanos y en la industria alimenticia y farmacéutica. Los altos precios en los mercados internacionales convierten a estos productos en una línea importante de desarrollo, sobre todo si la materia prima a utilizar es un desecho (Lía et al., 1996).

En los últimos años la industrialización de la biomasa genera gran cantidad de desechos (Tabla 1), los cuales son dispuestos en rellenos sanitarios, zanjas o en las riveras de los ríos, convirtiéndose de esta manera en una fuente de contaminación ambiental. Sin embargo, estos desechos muestran un alto potencial para ser utilizados como materia prima en otros procesos industriales (Vega, 1998).

Dentro de los desechos agroindustriales se encuentran los originados por el procesamiento de la piña, cuyo cultivo y exportación como producto no tradicional ha venido en aumento en los últimos años (Figura 2). Para 2010 y 2011, el crecimiento ha sido exponencial. Las exportaciones de piña aumentaron un $4.9 \%$ para abril de 2011 en comparación con el mismo período de 2010

En Costa Rica la industrialización de la piña genera un $50 \%$ de desechos; el corazón y la cáscara representan el $30 \%$, equivalente a una cantidad cercana a las 3.000 toneladas anuales (Vega, 1997, 1998; Bell, 1995). En la Tabla 2 se presentan algunas estadísticas relacionadas con la producción de desechos. 


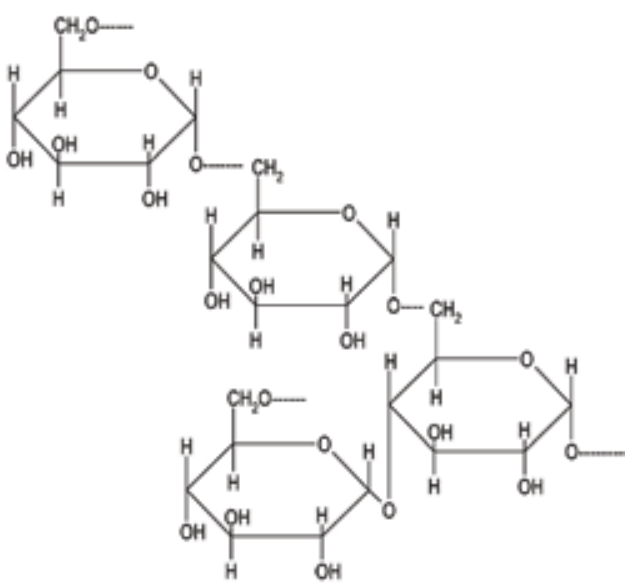

Figura 1. Molécula de dextrano.

\begin{tabular}{|c|c|}
\hline Tipo de desecho & Porcentaje $( \pm \mathbf{0 . 5})$ \\
\hline Ordinario & 13,6 \\
\hline Peligroso & 0,4 \\
\hline Agroindustriales & 86,0 \\
\hline
\end{tabular}

Tabla 1. Producción de desechos en Costa Rica (Vega, 1998).

En el caso de las cáscaras de piña, se ha aprovechado su parte fibrosa en la obtención de derivados lignocelulósicos (Bell, 1995; Lopretti, 2002) y el líquido resultante queda como un desecho que ha sido poco evaluado. Dicho jugo presenta un contenido de sacarosa de aproximadamente $5 \%$, lo que lo convierte en un sustrato adecuado para la obtención de dextranos utilizando una cepa del género Leuconostoc.

El objetivo de este trabajo es la producción biotecnológica de dextranos de alto peso molecular, utilizando como sustrato la sacarosa presente en el jugo de las cáscaras de piña y como inóculo la cepa Leuconostoc mesenteroides, var. mesenteroides ATCC 10830 (NRRL B-512F).

\section{Materiales y Métodos}

\section{Sustrato}

El jugo se obtuvo del prensado de los desechos del procesamiento de la piña (Ananas comusus), en una de las plantas procesadoras de la fruta. El jugo fue pretratado con hidróxido de sodio $1 \mathrm{~N}$, hasta un $\mathrm{pH}$ de 5,5 y se pasteurizó calentándolo a $61,5{ }^{\circ} \mathrm{C}$ por 3 minutos con enfriamiento hasta la temperatura inicial. Este proceso se realizó tres veces consecutivas.

\section{Análisis químicos del sustrato}

El porcentaje de sacarosa y otros azúcares fue determinado mediante HPLC (Shimadzu 10A, columna y precolumna de aminos, fase móvil acetonitrilo/agua en una relación $80 / 20$, a $30{ }^{\circ} \mathrm{C}$, flujo 2 $\mathrm{mL} / \mathrm{min}$, detector de índice de refracción). La determinación de ácidos totales se realizó por titulación con hidróxido de sodio $0.100 \mathrm{~N}$, los metales traza por absorción atómica, proteínas por el método de Biuret,

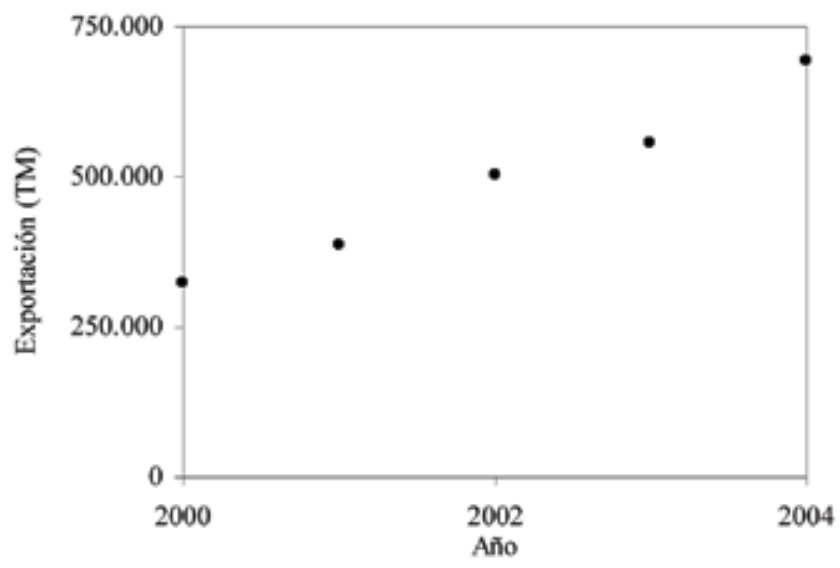

Figura 2. Volúmenes de exportación de piña entre 2000 y 2004. Fuente: CENPRO.

\begin{tabular}{|c|c|}
\hline Tipo de desecho & Porcentaje \\
\hline Área sembrada & $7.000 \mathrm{Ha}$ \\
\hline Producción anual & $240.000 \mathrm{~T} . \mathrm{M}$. \\
\hline Exportación & $90 \%$ \\
\hline Aprovechamiento del fruto & $35-50 \%$ \\
\hline Corona & $12 \%$ \\
\hline Corazón & $9 \%$ \\
\hline Cáscaras & $32 \%$ \\
\hline
\end{tabular}

Tabla 2. Estadísticas relacionadas con la industrialización de la piña (1994). Fuente: CENPRO.

cenizas por ASTM D1102- 84 y pH por medio de un peachímetro calibrado.

\section{Análisis microbiológicos}

La caracterización microbiológica del jugo de las cáscaras de piña fresco y sin recibir tratamiento previo incluyó la determinación del índice de coliformes fecales y totales, con la técnica de tubos múltiples (Bell y Carrera, 1992), conteo total de aerobios y mesófilos, utilizando las técnicas por vaciado y rayado, y conteo de hongos y levaduras (Bell, 1970).

\section{Microorganismo empleado}

Se utilizó la bacteria Leuconostoc mesenteroides, var. mesenteroides ATCC 10830.

\section{Inóculo}

El jugo de piña fue inoculado con un cultivo de Leuconostoc mesenteroides incubado durante 18 horas a $29{ }^{\circ} \mathrm{C}$ en un medio de cultivo artificial, el cual contiene para $1 \mathrm{~L}$ de agua: $20 \mathrm{~g}$ de triptona, $4 \mathrm{~g}$ de cloruro de sodio, 1,5 $\mathrm{g}$ de acetato de sodio, $0,5 \mathrm{~g}$ de ácido ascórbico, elementos traza (Ca, Mn, Fe, Mg), $15 \mathrm{~g}$ de sacarosa y 8,76 g de extracto de levadura y $20 \mathrm{~g}$ de agar. El pH del medio se ajustó a 5,5 con ácido clorhídrico (Vega, 1998) antes de autoclavarse $\left(121^{\circ} \mathrm{C}\right.$, 20 minutos).

\section{Obtención y purificación de dextranos}

El jugo del desecho de piña inoculado se incubó por 18 horas a $29^{\circ} \mathrm{C}$, sin agitación. Al finalizar el período de incubación se centrifugó por 30 minutos a $5000 \mathrm{rpm}$, para eliminar las células. Al sobrenadante se 
le adicionó etanol al $95 \%$ hasta una proporción 1 a 1 en volumen. Se centrifugó a $5000 \mathrm{rpm}$ por 30 minutos (Vega, 1998).

El sobrenadante se descartó y al precipitado blanco se le agregó agua hasta disolverlo, para iniciar el proceso de purificación. Se centrifuga de nuevo en las mismas condiciones y al sobrenadante se le agrega etanol (1/1 volumen). Se realizó la curva de precipitación para comprobar esta relación 1:1. El proceso se repite dos veces más.

El dextrano obtenido se secó, se determinó el rendimiento de producción, su viscosidad, el peso molecular por viscosidad y grupos funcionales por espectroscopía de infrarrojo.

\section{Caracterización de dextranos}

\section{Viscosidad y peso molecular viscosimétrico}

Los análisis se realizaron según el ASTM D445 y D2515 (5) con viscosímetros Cannon-Fenske, en un baño de agua a una temperatura de $40{ }^{\circ} \mathrm{C}$.

\section{Grupos funcionales}

Se utilizó un equipo de Espectroscopía de infrarrojo (FTIR) PARAGON 1000 PERKIN ELMER.

\section{Hidrólisis del Dextrano}

Lopretti (2002). Se preparó una disolución del dextrano al $6 \%$ $\mathrm{P} / \mathrm{V}$ en agua destilada. Se le añadió $\mathrm{HCl}$ concentrado hasta alcanzar una concentración de $0.1 \mathrm{~N}$. Se calentó entre $80-90^{\circ} \mathrm{C}$ con agitación.

$\mathrm{Al}$ inicio de la hidrólisis se tomó una alícuota de la disolución. El proceso se repite cada cierto tiempo, se coloca en un balón aforado y se lleva a un $\mathrm{pH}$ de 7 con $\mathrm{NaOH}$. Se le determina la viscosidad.

\section{Síntesis y caracterización de Hierro-dextrano}

(Bell, 1995). La metodología abarca tres etapas. En la primera ocurre la hidrólisis del dextrano técnico en solución al $10 \%$ de ácido clorhídrico (32-37 \%). La hidrólisis se regula por medio de análisis de viscosidad intrínseca hasta valor $0,05-0,1$ y se detiene neutralizando y enfriando la mezcla de reacción. Finalmente se filtra utilizando ayuda filtrante. Este proceso de hidrólisis permite obtener una solución de dextrano de bajo peso molecular, homogéneo y adecuado para ser acomplejado sin dar lugar a dextranos libres de alto peso molecular.

En la segunda etapa se realiza la síntesis del hierro-dextrano, partiendo de la reacción lenta entre el $\mathrm{FeCl}_{3} 0,5-2 \mathrm{M}$ y el $\mathrm{Na}_{2} \mathrm{CO}_{3}$ a 10 $20 \%$. Se ajusta pH en 8-12 con hidróxido sódico al $20 \%$. La solución se estabiliza con calor. Se enfría y se ajusta el pH con $\mathrm{HCl}$ 1:1 hasta valores entre 4-7. La ejecución de esta etapa, según se señala, reduce el contenido de hierro libre que afecta la estabilidad del complejo.

En la tercera etapa se filtra el producto empleando ayuda filtrante y se añade propil y metil parabenos en relación 1:4 como preservantes. Se caracteriza su contenido de hierro y su $\mathrm{pH}$.

\section{Resultados y Discusión}

Con respecto a la caracterización del jugo de piña, se procedió a hacer el análisis por separado del jugo extraído de las cáscaras de la piña y del corazón del fruto. Como los resultados obtenidos no indican diferencias apreciables en cuanto al $\mathrm{pH}$ y al contenido de sacarosa, en posteriores usos se utilizan indistintamente, sin separar los residuos (Tabla 3).

La selección del sustrato se realizó con base en los requerimientos de la bacteria Leuconostoc mesenteroides, la cual necesita para su reproducción un $\mathrm{pH}$ de $5,5,20-30{ }^{\circ} \mathrm{C}$ y $2 \%$ de sacarosa. El contenido de sacarosa del jugo de piña posterior a la esterilización queda en 1,4 $\%$. En la Tabla 4 se presentan los resultados obtenidos con respecto a algunos elementos traza.

El análisis de sacarosa al final de la obtención de dextrano fue de $0,13 \%$, lo que demuestra que durante el proceso de fermentación la mayoría de la sacarosa presente fue consumida por el microorganismo y parte de ella transformada en dextranos y fructuosa.

El rendimiento de dextranos obtenido fue de $6,3 \mathrm{~g} / 1$ de jugo de las cáscaras de piña. Este rendimiento es superior si se compara con el obtenido utilizando otros sustratos (Lopretti, 2002).

En la Figura 3 se observan los resultados obtenidos en la determinación de la curva de precipitación para la purificación del dextrano. Se comprobó que la cantidad necesaria para precipitar la máxima cantidad de un dextrano en medio acuoso utilizando alcohol $95 \%$ corresponde a una relación de 1:1 agua-etanol.

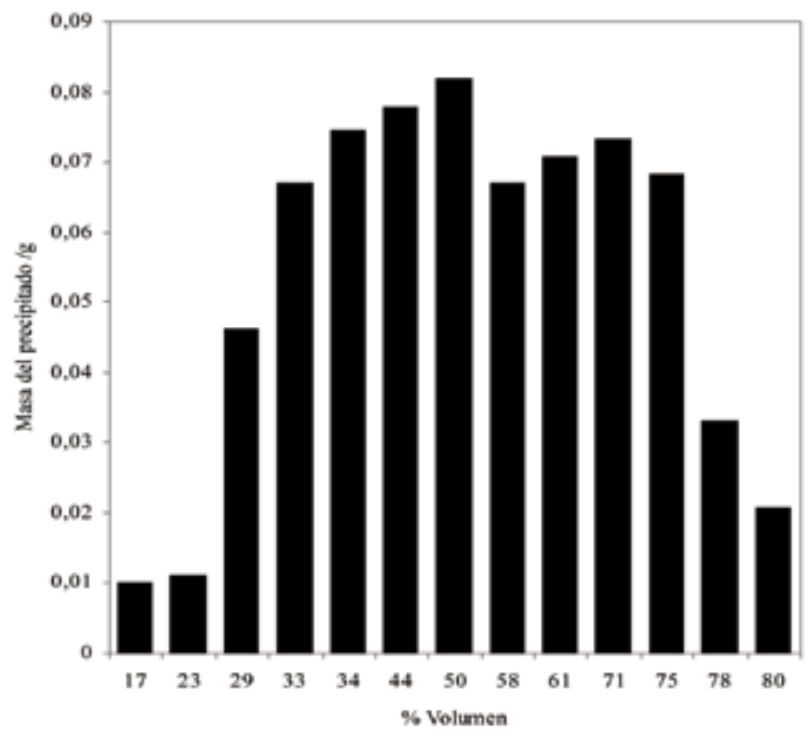

Figura 3. Resultados obtenidos en la determinación de la curva de precipitación para la purificación del dextrano.

\begin{tabular}{|l|c|c|c|c|c|}
\hline Desecho & ph $( \pm \mathbf{0 . 0 5})$ & Acidez $^{*}( \pm \mathbf{0 . 0 5})$ & Sacarosa $( \pm \mathbf{0 . 0 5 \% )}$ & Cenizas $( \pm \mathbf{0 . 0 5 \%})$ & Proteína $( \pm \mathbf{0 . 1} \mathbf{~ m g} / \mathbf{m L})$ \\
\hline Cáscara de piña & 3,70 & 70,56 & 4,16 & 0,43 & 10,4 \\
\hline Corazón de pina & 3,90 & 47,62 & 5,89 & 0,26 & 4,4 \\
\hline
\end{tabular}

Tabla 3. Caracterización de los desechos de piña sin tratar. * $\mathrm{mL}$ de $\mathrm{NaOH} 0.1 \mathrm{~N} / 100 \mathrm{~g}$ de jugo

\begin{tabular}{|l|c|c|c|c|}
\hline Elemento & Ca & Mg & Fe & Mn \\
\hline$\%$ & $0,015 \pm 0,001$ & $0,009 \pm 0,001$ & $0,0004 \pm 0,0001$ & $0,0011 \pm 0,0001$ \\
\hline
\end{tabular}

Tabla 4. Determinación de elementos traza de los desechos de piña. 
Con respecto a los resultados de la viscosidad relativa (Tabla 5), la diferencia observada entre el resultado teórico del peso molecular y el obtenido experimentalmente corresponde al ancho de la curva de peso molecular, es decir, parte de la viscosidad depende de las fracciones de menor peso molecular, de un material monodisperso. El resultado corresponde, por lo tanto, al máximo pico observado. Se calculó que el peso molecular del dextranos de piña es cercano a 1 millón de Daltons.

\begin{tabular}{|c|c|c|}
\hline Muestra & Viscosidad relativa & $\begin{array}{c}\text { Resultado MW } \\
\text { (Daltons) }\end{array}$ \\
\hline Dextrano de piña & 6,4 & 960000.00 \\
\hline Patrón de 40000 & 1,6 & 35000 \\
\hline Patrón de 70000 & 1,7 & 60000 \\
\hline
\end{tabular}

Tabla 5. Resultados obtenidos en la determinación de la viscosidad y de los pesos moleculares viscosimétricos de los dextranos.

El espectro de infrarrojo mostró los picos característicos de un material celulósico a 3300 y $2900 \mathrm{~cm}^{-1}$, correspondientes a los grupos $\mathrm{OH}$. Con los resultados observados en los espectros de infrarrojo, se concluye que el material producido corresponde al dextrano.

Finalmente, el hierro dextrano sintetizado presentó un color rojo oscuro, con un $\mathrm{pH}$ cercano a 5, un contenido de $10 \% \mathrm{p} / \mathrm{v}$ de hierro, muy similar al descrito en la literatura (Bell, 1995; Bell, 1992).

\section{Conclusiones}

Se concluye que la metodología usada para la obtención de dextranos y de hierro dextranos a partir de la sacarosa presente en los desechos de cáscara de piña da buenos resultados, incluso superiores con respecto a los mencionados en la literatura.

Además, eventualmente se aprovecharían materiales considerados como subproductos de procesos industriales, económicamente subutilizados, y que producen alta contaminación ambiental para la obtención de materiales de mayor valor agregado.

De esta manera se pretende que con el aporte de los centros de investigación, las compañías industrializadoras de esta fruta disminuyan el porcentaje de sus desechos y, por ende, su impacto negativo en el medio ambiente, y que a la vez se beneficien con una entrada extra con la obtención de productos de un mayor valor agregado que el de los desechos. Se combina de esta manera un mejoramiento en la calidad de vida del costarricense y un incremento en las ganancias de los productores de la fruta.

\section{Referencias}

- ASTM INTERNATIONAL (United States). D1102: Standard test method for ash in wood. Conshohocken: ASTM, 2007.

- ASTM INTERNATIONAL (United States). D445: Standard test method for kinematic viscosity of transparent and opaque liquids (and calculation of dynamic viscosity). Conshohocken: ASTM, 2012.

- ASTM INTERNATIONAL (United States). D2515: Standard specification for kinematic glass viscosity. Conshohocken: ASTM, 1996.

- BARKER, P.E.; AJONGWEN, N.J. The productions of the enzyme dextransucrase using nonaerated fermentation techniques. En: Biotechnol. Bioeng. 1990, 37:703-707

- BELL GARCÍA, Antonio. Producción del complejo de dextrana de hierro de uso antianémico. Cuba. 22490. A61K. 1998-12-30.

- BELL, A.; CARRERA, E. Optimización de la hidrólisis química de la Dextrana técnica cubana para la obtención de dextrana con bajo peso molecular. En: Revista ICIDCA. 1992, XXVI( 2):[s.p.]

- BELL, A.; MALEK, J. Boletín sobre los derivados de la caña de azúcar. 1970, 7(2):[s.p.]

- CENPRO. Información consultada en el "Centro para la Promoción de las Exportaciones y de las Inversiones”, San José, Costa Rica.

- GONZÁLEZ, E.; MONCTEZUMA, A. Biotechnology for the processing of pineapple waste. En: Industry and Environment. 1985, $8(4): 20$.

- LÍA TORRES, L.; SIBAJA, M.; MOYA, M.; LUQUE, J.; LOPRETTI, M. Conversión del jugo de cáscaras de piña a biopolímeros. [s.1.]: [s.n.], 1996.

- LOPRETTI, M. Producción simultánea de dextrano y fructosa a partir de desechos agroindustriales en Iberoamérica, aspectos cientificos, técnicos y económicos. [s.1]: CYTED, 2002.

- MONSAN, P. On the production of dextran by free and immobilized sucrosa. En: Biotechnol. Bioeng. 1981, 23:2027-2037.

- VEGA, J. Informe anual producción de dextranos de desechos agroindustriales. Heredia: POLIUNA, 1997.

- VEGA, J. Informe del Curso Internacional Obtención de Dextranos a partir de agua de Coco. [s.1.]: [s.n.], 1998. 